\title{
Where Does Fear Lead Us: Antiretroviral Treatment Adherence in Maputo
}

\author{
Marta Moreno, Margarida Gaspar de Matos, António Jorge Cabral \\ Centro de Malária e Doenças Tropicais (CMDT), Instituto de Higiene e Medicina Tropical, Lisboa, Portugal \\ Email: mmoreno.psicologia@gmail.com
}

Received 23 January 2014; revised 28 February 2014; accepted 8 March 2014

Copyright (C) 2014 by authors and Scientific Research Publishing Inc.

This work is licensed under the Creative Commons Attribution International License (CC BY).

http://creativecommons.org/licenses/by/4.0/

(c) (i) Open Access

\section{Abstract}

This research aims to deepen knowledge on the role of fear on ART adherence of patients who live in Maputo district in Mozambique, including differences on age, gender and schooling level, on their previous knowledge about HIV and ART and on the impact of the discrimination experiences on the ART adherence. The participants are 602 ART patients living in Maputo district between 21 and 56 years old. The findings reveal that more men than women have interrupted the treatment. Those who did it at least once have more than 39 years old. There are more reports of non-interruption of the treatment on patients who have never been to school or who have been in the high school or more advanced studies. Those who reported that have never interrupted the treatment have more previous knowledge about HIV and the treatment; have never been discriminated and have less fear of being marginalized by being HIV+. Most of those who have interrupted the treatment have already been discriminated by nurses or friends. As fear is automatically processed in our brain, specific contexts of fear related to ART where studied as well as the impact of the fear of those contexts on the behaviors of adherence or of treatment interruption. The results reflect the need to develop national educational policies regarding emotional awareness, adequate emotional support and coping strategies in the context of Fear and of ART adherence. New policies need to address gender and age differences as well as health education access to ART patients, attempting to the stigma and the fear of discrimination as a present element of influence on ART adherence. The study also validates the role of health professionals as high responsible elements on the health of the ART individuals.

\section{Keywords}

ART Adherence; Discrimination; Gender; Age; Fear; Education; Health Professionals; Mozambique

\section{Introduction}

According to WHO annual report, in 2012 in African Region there were almost 6.4 million people receiving 
Antiretroviral therapy (ART) in low and middle-income countries. In Mozambique, it was reported that 309,851 people were receiving ART covering even only $45 \%$ of the estimated eligible people for the treatment [1].

Concerns about HIV treatment adherence have been in the highlight of research in the field. A growing body of literature points that even having different factors that can influence the success or failure of ART, it is still in the line of the need to maintain a consistent therapeutic program [2] [3]. In most countries surveyed in Demographic and Health Surveys in Who African Region showed that for example when the ART is started, about one quarter of the patients temporarily interrupt the treatment and another quarter are lost in three years.

Effective management of HIV disease requires high levels of ART adherence [4] [5], because incomplete adherence can dramatically affect the virological control and subsequently disease progression, as well as contributes to elevated rates of antiretroviral resistance [5]. Therefore, ensuring that HIV-positive persons maintain high levels of ART adherence is of critical clinical importance as well as it is the study of its predictors.

Characteristics of ART medication and the influence of demographic and social factors have been addressed on researches during the last years [6]-[8].

Attempting to gender differences on coping with a disease, on searching for help of others or for information about health, studies have presented a discrepancy on adherence to antiretroviral medications between HIV-infected men and women. This includes evidence that HIV-infected women face different barriers to adherence than do their male counterparts [9] [10] and women are less likely to adhere to ART [11].

In the context of HIV infection, the sense of belonging, of inclusion and the social support has been connected to better coping [12]-[17] better treatment adherence , and slower progression to AIDS [18]-[21].

Studies have also indicated that attempts to support or help are not always perceived as helpful by the one who receives it [22]. Well-intentioned support attempts may have been seen as oppressive and constraining by their recipients [23] [24]. Therefore social relationships can also improve discrimination and isolation especially when it touches the base of judgment and stigma, [22] as well as the development of fear, well documented as one of the six core universal emotions [25]. Fear is a basic survival mechanism that occurs in the response to a specific stimulus which is perceived in the amygdala as a risk of significant health, wealth, security or of anything valuable [26] [27]. The fear of not being able to complete the treatment, of the side effects, of being in stigma presence during the treatment, have a major concern when we address the study of ART adherence.

Stigma is defined as negative attitudes and behaviours assumed by any person towards another one or even only to a concept [28] [29], which in concerns of ART adherence, studies have already presented how it interferes with the effectiveness of the treatment, reducing it [28]-[33].

Furthermore, adherence to ART is influenced by medication side effects as: numbness, tingling, fevers, skin rashes, nausea, vomiting and pain... There is evidence that such side effects are predictive of poor adherence to HAART [34].

The purpose of this study is to deepen knowledge of ART adherence on patients who live in Maputo district in Mozambique, including differences on age, gender and schooling level, on their previous knowledge about HIV and ART, on the impact of the stigma discrimination experiences on the ART adherence as well as role of fear as a predictor of treatment adherence.

\section{Study Setting}

This exploratory study was conducted in Maputo district in Mozambique among a convenience sample of patients in the Military Hospital (HIV Cohort) and DREAM NGO. The Military Hospital is an urban public hospital and the only one which still has the HIV clinic, and Dream NGO is the largest single provider of HIV care in Maputo City, receiving patients from all district. The Institutional Review Board approved this study. After having received authorization, participants were voluntarily solicited to fill out the questionnaires and the study's aim were explained to them. To protect participants and their anonymity, no information regarding identity is required on the questionnaire. Participants, one by one, answered the questionnaire, sitting in a desk alone with the researcher, thus guaranteeing confidentiality. The fact that the investigator is unknown to the patients, that she is not a member of the health care team is a guarantee of patient's anonymity and limits this bias (e.g. the patients were not afraid of being criticized for poor adherence). This study strictly followed the guidelines for human rights protection.

\subsection{Participants}

Person in antiretroviral therapy (ART) for HIV aged 18 years and above who attended the clinic for a routine 
clinical care appointment between September 2011 and May of 2012 were eligible for the study. Patients were not compensated for participation. Patients unable to provide informed consent (e.g. participants with severely impaired cognitive functioning) or those who could not speak Portuguese were excluded from the study. The sample consists of 602 ART patients living in Maputo district between 21 and 56 years old.

\subsection{Measures}

A questionnaire was developed to access to the elements on research: socio-demographic characteristics, family disclosure and support relationships, relationship with the HIV diagnose, relationship with ART, relationship with the Health Team, Sexuality, Social discrimination and Violence, general knowledge about TARV.

Socio-demographic characteristics were assessed through the following items-gender (male/female), age (included as a continuous variable), schooling (None, $1^{\text {st }}$ Cycle ( 1 to 4 years of school), $2^{\text {nd }}$ Cycle (5 to 6$)$ ), $3^{\text {rd }}$ Cycle (7 to 9), Secondary School (10 - 12), University Degree, Others), marital status (single, married, unmarried cohabitation, divorced, widower), household (live alone, live only with children, live only with life partner, live with children and life partner, live with children and other relatives, live with relatives).

From the questionnaire the following questions were specifically chosen for this study: 1) Did you interrupt the treatment at least once (yes/no), 2) Previous knowledge about HIV before doing the test (yes/no), 3) Discriminated as HIV+ (yes/no), 4) By whom have you been discriminated (doctors, nurses, relatives, friends, work colleagues), 5) fear of being recognized as HIV+ (yes/no), 6) How would you say this fears are constantly on you (1 to 5): a) Fear of medication side effects, b) Fear of forgetting to take pills on time, c) fear of failing ART one or more days, d) Fear of not feeling is getting better, e) fear of being known that I take ART medication, f) fear of being recognized by other patients.

\subsection{Data Analysis}

The data were analyzed using the Statistical Package for Social Sciences (SPSS) version 19.

Chi-square $\left(\chi^{2}\right)$ test and adjusted residuals was used to analyze the differences between those who have or have not interrupted the treatment. The level for statistical significance was set at $\mathrm{p}<0.05$. Only significant results were discussed. A logistic regression was conducted considering "having interrupted the treatment" as a dependent variable and using gender, fear or medication collateral effects, fear of forgetting to take ART pills on schedule, fear of failing ART one or more days, fear of not feeling is getting better, fear of knowing that I take ART medicines, fear of being recognized by other patients, as independent variables.

The items fears towards ART were answered by the participants in a 5 -point rated scale $(1=$ very lower; $2=$ lower; 3 = moderate, 4 = high; 5 = very high).

\section{Results}

Demographic characteristics of these individuals are shown in Table 1. There are more females (74.8\%) than males (25.2\%) in the sample. Most participants have age between 21 and 29 years old (33.2\%) and have completed the Second Cycle of School (33.1\%). Only 6.3\% of the individuals have never completed any school level and none $(0 \%)$ have completed any University degree.

The analysis of the treatment interruption presented statistical significant differences.

Most patients that have interrupted the treatment: are men $\left(36.8 \% ; \chi^{2}(1)=20.038\right.$; $\left.\mathrm{p}=0.000\right)$; have ages between 48 and 56 years old $\left(37.3 \% ; \chi^{2}(3)=94.152, \mathrm{p}=0.000\right)$, have finished the 1 st Cycle of schooling $(36.3 \%$; $\left.\chi^{2}(4)=52.794, p=0.000\right)$, have already been discriminated as seropositive $\left(78.8 \%, \chi^{2}(1)=6.860, p=0.009\right)$, have been discriminated by friends $(46.7 \%)$ and nurses $\left(35.5 \% ; \chi^{2}(4)=52.763, \mathrm{p}=0.000\right)$.

Considering those who have never interrupted the treatment, we have more: women (80.2\%); ART patients with ages between 21 and 29 years old (41.3\%); who have never completed a cycle of studies (9.3\%) or have finished the Secondary school (34\%); who didn't have previous knowledge about HIV $\left(46.1 \% ; \chi^{2}(1)=5.415\right.$, p $=0.02)$; who have never been discriminated as seropositive (31.5\%), or was discriminated by doctors (14.3\%), relatives (16.8\%) and work colleagues (20.4\%); and fear being discriminated as $\mathrm{HIV}+\left(75.3 \% ; \chi^{2}(1)=22.535\right.$; $\mathrm{p}=0.000)$.

Using a binary logistic regression we obtained an adjusted model (Hosmer and Lemeshow $\chi^{2}(8)=10,789$; $\mathrm{p}$ $=0.214$ ) and the regression equation explained $27.7 \%$ of the variance (Nagelkerke $\mathrm{R}^{2}=0.277$ ) and $89.5 \%$ of 
Table 1. Demographic characteristics of the patients.

\begin{tabular}{|c|c|c|c|c|c|c|c|}
\hline & \multicolumn{2}{|c|}{ Yes $(\mathrm{N}=)$} & \multicolumn{2}{|c|}{ No $(\mathrm{N}=)$} & \multicolumn{2}{|c|}{ Total ( $\mathrm{N}=)$} & \multirow{2}{*}{$\chi^{2}$} \\
\hline & $\mathrm{N}$ & $\%$ & $\mathrm{~N}$ & $\%$ & $\mathrm{~N}$ & $\%$ & \\
\hline \multicolumn{8}{|l|}{ Gender } \\
\hline Female & 122 & 63.2 & 328 & 80.2 & 450 & 74.8 & \multirow[t]{2}{*}{$20.038^{*}$} \\
\hline Male & 71 & 36.8 & 81 & 19.8 & 152 & 25.2 & \\
\hline \multicolumn{8}{|l|}{ Age } \\
\hline From 21 to 29 & 31 & 16.1 & 169 & 41.3 & 200 & 33.2 & \multirow{4}{*}{$94.152^{*}$} \\
\hline From 30 to 38 & 45 & 23.3 & 125 & 30.6 & 170 & 28.2 & \\
\hline From 39 to 47 & 45 & 23.3 & 83 & 20.3 & 128 & 21.3 & \\
\hline From 48 to 56 & 72 & 37.3 & 32 & 7.8 & 104 & 17.3 & \\
\hline \multicolumn{8}{|l|}{ Schooling Level } \\
\hline None & 0 & 0 & 38 & 9.3 & 38 & 6.3 & \multirow{7}{*}{52.794} \\
\hline 1st Cycle & 70 & 36.3 & 91 & 22.2 & 161 & 26.7 & \\
\hline 2nd Cycle & 72 & 37.3 & 127 & 31.1 & 199 & 33.1 & \\
\hline 3rd Cycle & 51 & 26.4 & 103 & 25.2 & 154 & 25.6 & \\
\hline Secondary School & 0 & 0 & 50 & 34 & 50 & 8.2 & \\
\hline University Degree & 0 & 0 & 0 & 0 & 0 & 0 & \\
\hline Other & 0 & 0 & 0 & 0 & 0 & 0 & \\
\hline \multicolumn{8}{|l|}{ Previous Knowledge } \\
\hline Yes & 194 & 53.9 & 261 & 63.8 & 365 & 60.6 & \multirow[t]{2}{*}{$5.415^{*}$} \\
\hline No & 89 & 46.1 & 148 & 36.2 & 237 & 39.4 & \\
\hline \multicolumn{8}{|l|}{ Discriminated as HIV+ } \\
\hline Yes & 152 & 78.8 & 280 & 68.5 & 482 & 71.8 & \multirow[t]{2}{*}{$6.860^{*}$} \\
\hline No & 41 & 21.2 & 129 & 31.5 & 170 & 28.2 & \\
\hline \multicolumn{8}{|l|}{ Discriminated by } \\
\hline Doctors & 12 & 7.9 & 40 & 14.3 & 52 & 12 & \multirow{5}{*}{$52.763^{*}$} \\
\hline Nurses & 54 & 35.5 & 64 & 22.9 & 118 & 27.3 & \\
\hline Relatives & 1 & 0.7 & 47 & 16.8 & 48 & 11.1 & \\
\hline Friends & 71 & 46.7 & 72 & 25.7 & 143 & 33.1 & \\
\hline Work colleagues & 14 & 9.2 & 57 & 20.4 & 71 & 16.4 & \\
\hline \multicolumn{8}{|c|}{ Fear of being identified as HIV + } \\
\hline Yes & 177 & 91.7 & 308 & 75.3 & 485 & 80.6 & \multirow[t]{2}{*}{$22.535^{*}$} \\
\hline No & 16 & 8.3 & 101 & 24.7 & 117 & 19.4 & \\
\hline
\end{tabular}

In bold—values that correspond to an adjusted residual $\geq|1.9| \cdot{ }^{*} \mathrm{p} \leq 0.01$

cases that didn't interrupt the treatment. In this model, the condition of “treatment interruption" is explained by the variables: gender (men with 0.3 times greater likelihood of being in this group) [OR 0.325; 95\% CI 0.207 0.512; $\mathrm{p}=0.000$ ], "fear of knowing that I take ART medication" (who reported higher values are with 1.9 times 
greater likelihood of being in this group) [OR 1.923; 95\% CI 1.470 - 2.515; p = 0.000], "fear of not feeling it's getting better" (who reported lower values are with 0,7 higher likelihood of being in this group) [OR 0.712; 95\% CI $0.623-0.814 ; \mathrm{p}=0.000$ ], "fear of forgetting to take the pills on schedule" (who reported higher values are with 2.65 times greater likelihood of being in this group [OR 2.55; 95\% CI $1.853-3.507 ; \mathrm{p}=0.000$ ] (see Table 2).

\section{Discussion}

Findings provided baseline data on knowledge about characteristics of ART patients adherence in Maputo district and the impact of Fear on treatment adherence.

The level of self-reported adherence evaluated as treatment interruption, is superior on men than on women. Results attempting gender adherence contrast the literature, where is stated that usually women are less likely to adhere to ART [11] However are consistent with WHO 2013 report where is stated that in most regions of the world, and primarily on those with a high burden of HIV infection in African Region, women are more likely than men to access to ART.

Such findings increase our attention, once according literature [35] women are more likely to miss HIV appointments, what contrasts our data. In our accidental survey women were also more frequent on going to the HIV Clinic appointments during the time that we were doing the research, with a ratio of approximately $75 \%$ (women) to $25 \%$ (men). If women are taking care of the main things related to the antiretrovirals, concerns are higher to men. As our results show, men avoidance of the treatment and of the treatment appointments, compromise their information about HIV and ART as also their role and involvement on treatment. These results bring our attention to the health political need to become closer to men when ART adherence is the concern. Men need specific attention and specific strategies might be need on new approaches development and in involving men more effectively on their HIV health care.

It is therefore considered that the results on age and schooling level need to be addressed together. Not surprisingly the results reveal that older people are those who more interrupt the treatment in comparison to the youngest (21 to 29 years old) ones which are those who have never done it. Besides the consideration that elders might be in treatment longer than the youths so they have been exposed for larger periods of time to the adversities and difficulties of treatment adherence, also the schooling level of elders, specially in Mozambicans with this age (between 48 and 56 years old) tend to be lower ( $1^{\text {st }}$ cycle) than the one of the youths (secondary school). Literature calls the attention to how patients with low literacy usually have the highest reported rate of non-adherence (52.2\%) and individuals with marginal literacy skills were the least likely to self-report missing any dose of antiretroviral medications (19.5\%) [33] [34] what matches our results.

Despite this considerations, would like to bring awareness to the need to keep protecting those who because are elder and/or have lower schooling age are not so exposed to media and formal information about HIV, AIDS and the treatment, so special AIDS health programs need to be and to keep being developed to this part of the population, and a special attention to the health professionals and activists to their important role in addressing this population and their lower literacy resources.

Multiple studies indicate the influence of the role of the knowledge of treatment regimens and cognitive de-

Table 2. Predictors of treatment interruption.

\begin{tabular}{|c|c|c|c|c|c|c|}
\hline & $\mathrm{B}$ & S.E. & $\mathrm{P}$ & OR & \multicolumn{2}{|c|}{ CI (95\%) } \\
\hline Gender & -1.123 & 0.231 & 0.000 & 0.325 & 0.207 & 0.512 \\
\hline Fear of medication side effects & 0.033 & 0.063 & 0.603 & 1.033 & 0.913 & 1.169 \\
\hline Fear forgetting to take pills on schedule & 0.936 & 0.163 & 0.000 & 2.550 & 1.853 & 3.507 \\
\hline Fear of failing ART one or more days & -0.077 & 0.093 & 0.408 & 0.926 & 0.772 & 1.111 \\
\hline Fear of not feeling is getting better & -0.339 & 0.068 & 0.000 & 0.712 & 0.623 & 0.814 \\
\hline Fear of knowing I take ART medication & 0.654 & 0.137 & 0.000 & 1.923 & 1.470 & 2.515 \\
\hline Fear of being recognized by other patients & -0.068 & 0.121 & 0.573 & 0.934 & 0.737 & 1.184 \\
\hline
\end{tabular}

B: the coefficient for the constant in the null model; OR: adjusted odds ratio; CI: confidence interval. 
mands related to the complexity of ART pharmacotherapy as factors that may influence the level of adherence and results indicated that personal HIV knowledge and appointment adherence were associated [36]-[39]. Surprisingly our results are not consistent with literature, revealing that patients who have never interrupted the treatment are those who didn't have any previous knowledge about HIV/AIDS before doing the test. Although this results might bring our attention to the role that the first HIV appointment has as a good first providing moment of correct information about the virus and the treatment, and also as past beliefs about the treatment might have been influencing negatively the adherence of our participants.

Discrimination and stigma show concordant values in our research. Those who have interrupted the treatment at least once are those who have already been discriminated as seropositive (78.8\%), and those who have never interrupted the treatment are those who live more in the fear of being identified as seropositive (75.3\%). Several studies have reported the role of social support in increasing or decreasing the stigma and effect of it on ART adherence [28]-[32].

Curiously the majority of participants who have interrupted the treatment were those who were discriminated by friends (46.7\%). Therefore social support cannot be uniformly assumed as an unconditional promoter of mental health outcomes. As have been shown in studies before [40] beside sociodemographic factors, also psychological factors influence the degree of adherence to antiretroviral therapy. According to results the Fear of the stigma and the Fear about the non-result of medication (fear to forget to take pills on schedule and the fear of not feeling it's getting better) have a major impact on treatment adherence, putting it on risk and even reducing it. These results increase our awareness to the importance of developing interventions on HIV and ART related emotional process that could early reduce the impact on adverse psychological responses, before automatic behaviour responses are activated. In this case, concerning the typical reactions neurologically involved in the presence of fear [41], we are touching the behaviours of fight (which might be adaptive when we consider ART adherence, because patients should be resilient enough that even through the fears of stigma or of treatment rules and procedures, they are able to still be committed with doing it), the behaviours of fly (which involves running out from situations where they might be in contact with fear) and finally the behaviours of freeze. Considering treatment adherence, this two last ones, fly or freeze, are the behaviours that need to be protected in our ART patients to have, because patients will miss more ART clinical appointments, or the ART schedule, if they feel overwhelmed by stigma and discrimination and as well depressive symptoms can be developed (isolation, exacerbate levels of fatigue, diminished ability to concentrate, feelings of worthlessness) which as known have a negative impact on HIV medication adherence [42], and which highlights the importance of the development of emotional and psychological interventions not only with the ART patients, but as well as with their families, activists, health professionals, as well as with all society (employers, co-workers, schools) creating and developing better support networks to help ART present and future patients to connect with Fear of HIV and ART in a more pro-adherence journey.

\section{Study Limitations}

This study has some limitations. First, because of the sensitive mature of the survey, findings are subject to social desirability bias. Second, an additional objective method (e.g. a count of returned pills) would have helped to improve the estimation of adherence level.

\section{Future Directions}

The results emphasize the need to understand the role of negative, as well as the positive emotional role on treatment adherence in response to stressful circumstances. Further studies should also address the comparison between specific knowledge of ART and it impact on treatment adherence. On future research we also expect to deepen the knowledge on the role of gender on treatment's adherence, and on the impact of the years in treatment on good adherence to ART.

\section{References}

[1] WHO, UNICEF, UNAIDS (2013) Global Update on HIV Treatment 2013: Results Impact and Opportunities. http://www.who.int/iris/bitstream/10665/85326/1/9789241505734_eng.pdf

[2] Wood, E., Hogg, R.S., Yip, B., Harrigan, P.R., O’Shaughnessy, M.V. and Montaner, J.S. (2003) Effect of Medication 
Adherence on Survival of HIV-Infected Adults Who Start Highly Active Antiretroviral Therapy When the CD4 + Cell Count Is 0.200 to $0.350 \times 10(9)$ Cells/L. Annals of Internal Medicine, 139, 810-816. http://dx.doi.org/10.7326/0003-4819-139-10-200311180-00008

[3] Wood, E., Hogg, R.S., Yip, B., Harrigan, P.R., O’Shaughnessy, M.V. and Montaner, J.S. (2004) The Impact of Adherence on CD4 Cell Count Responses among HIV-Infected Patients. Journal of Acquired Immune Deficiency Syndromes, 35, 261-268. http://dx.doi.org/10.1097/00126334-200403010-00006

[4] Patterson, D., Swindells, S., Mohr, J., Brester, M., Vergis, E., Squier, C., Wagener, M. and Singh, N. (2000) Adherence to Protease Innibitor Therapy and Outcomes in Patients with HIV Infection. Annals of Internal Medicine, 133, 21-30. http://dx.doi.org/10.7326/0003-4819-133-1-200007040-00004

[5] Deeks, S. (2003) Treatment of Antiretroviral Drug-Resistant HIV-1 Infection. Lancet, 362, 2002-2011. http://dx.doi.org/10.1016/S0140-6736(03)15022-2

[6] Boyer, S., Marcellin, F., Ongolo-Zogo, P., et al. (2009) Financial Barriers to HIV Treatment in Yaounde, Cameroon: First Results of a National Cross-Sectional Survey. Bulletin of the World Health Organization, 87, 279-287. http://dx.doi.org/10.2471/BLT.07.049643

[7] Byakika-Tusiime, J., Crane, J., Oyugi, J.H., et al. (2009) Longitudinal Antiretroviral Adherence in HIV? Ugandan Parents and Their Children Initiating HAART in the MTCT-Plus Family Treatment Model: Role of Depression in Declining Adherence over Time. AIDS and Behavior, 13, 82-91. http://dx.doi.org/10.1007/s10461-009-9546-x

[8] Tuller, D.M., Bangsberg, D.R., Senkungu, J., Ware, N.C., Emenyonu, N. and Weiser, S.D. (2009) Transportation Costs Impede Sustained Adherence and Access to HAART in a Clinic Population in Southwestern Uganda: A Qualitative Study. AIDS and Behavior, 14, 778-784. http://dx.doi.org/10.1007/s10461-009-9533-2

[9] Johnston, R. and Mann, T. (2000) Barriers to Antiretroviral Medication Adherence in HIV Infected Women. AIDS Care, 12, 377-386. http://dx.doi.org/10.1080/09540120050123774

[10] Applebaum, A., Richardson, M., Brady, S., Brief, D. and Keane, T. (2009) Gender and Other Psychosocial Factors as Predictors of Adherence to Highly Active Antiretroviral Therapy (HAART) in Adults with Comorbid HIV/AIDS, Psychiatric and Substance-Related Disorder. AIDS and Behavior, 13, 60-65. http://dx.doi.org/10.1007/s10461-008-9441-X

[11] Tapp, C., Milloy, M., Kerr, T., Zhang, R., Guilemi, S., Hogg, R., Montaner, J. and Wood, E. (2011) Female Gender Predicts Lower Access and Adherence to Antiretroviral Therapy in a Setting of Free Healthcare. BMC Infectious Diseases, 11, 86. http://dx.doi.org/10.1186/1471-2334-11-86

[12] Meacham, C.L. (1997) Women Living with HIV and AIDS: Relationships among Stress, Hopelessness, Coping and Perceptions of Social Support. University of Cincinnati, Cincinnati.

[13] Swindells, S., Mohr, J., Justis, J.C., Berman, S., Squier, C., Wagener, M.M., et al. (2009) Quality of Life in Patients with Human Immunodeficiency Virus Infection: Impact of Social Support, Coping Style and Hopelessness. International Journal of STD \& AIDS, 10, 383-391. http://dx.doi.org/10.1258/0956462991914302

[14] Kelly, J.A., Murphy, D.A., Bahr, G.R. and Kalichman, S.C. (1993) Outcome of Cognitive-Behavioral and Support Group Brief Therapies for Depressed, HIV-Infected Persons. American Journal of Psychiatry, 150, 1679-1686.

[15] Safren, S.A., Radomsky, A.S., Otto, M.W. and Salomon, E. (2012) Predictors of Psychological Well-Being in a Diverse Sample of HIV-Positive Patients Receiving Highly Active Antiretroviral Therapy. Psycho-Somatics, 43, 478-485. http://dx.doi.org/10.1176/appi.psy.43.6.478

[16] Leserman, J., Jackson, E.D., Petitto, J.M., Golden, R.N., Silva, S.G., Perkins, D.O., et al. (1999) Progression to AIDS: The Effects of Stress, Depressive Symptoms, and Social Support. Psychosomatic Medicine, 61, 397-406.

[17] Chesney, M.A., Chambers, D.B., Taylor, J.M. and Johnson, L.M. (2003) Social Support, Distress, and Well-Being in Older Men Living with HIV Infection. Journal of Acquired Immune Deficiency Syndromes, 33, S185-S193. http://dx.doi.org/10.1097/00126334-200306012-00016

[18] Wrubel, J., Stumbo, S. and Johnson, M.O. (2010) Male Same Sex Couple Dynamics and Support for HIV Medication Adherence: The Question of Received Social Support. Journal of Social and Personal Relationships, 27, 553-572. http://dx.doi.org/10.1177/0265407510364870

[19] Fogarty, L., Roter, D., Larson, S., Burke, J., Gillespie, J. and Levy, R. (2002) Patient Adherence to HIV Medication Regimens: A Review of Published and Abstract Reports. Patient Education and Counseling, 46, 93-108. http://dx.doi.org/10.1016/S0738-3991(01)00219-1

[20] Leserman, J., Jackson, E.D., Petitto, J.M., Golden, R.N., Silva, S.G., Perkins, D.O., et al. (1999) Progression to AIDS: The Effects of Stress, Depressive Symptoms, and Social Support. Psychosomatic Medicine, 61, 397-406.

[21] Johnson, M.O., Catz, S.L., Remien, R.H., Rotheram-Borus, M.J., Morin, S.F., Charlebois, E.D., et al. (2003) Theory Guided, Empirically Supported Avenues for Intervention on HIV Medication Nonadherence: Findings from the Healthy Living Project. AIDS Patient Care STDS, 17, 645-656. http://dx.doi.org/10.1089/108729103771928708 
[22] Lehman, D.R., Ellard, J.H. and Wortman, C.B. (1986) Social Support for the Bereaved: Recipients' and Providers' Perspectives on What Is Helpful. Journal of Consulting and Clinical Psychology, 54, 438-446. http://dx.doi.org/10.1037/0022-006X.54.4.438

[23] Coyne, J.C., Wortman, C.B. and Lehman, D.R. (1988) The Other Side of Support: Emotional over Involvement and Miscarried Helping. In: Gottlieb, B.H., Ed., Marshalling Social Support, Sage, Newbury Park, 305-330.

[24] Shinn, M., Lehman, S. and Wong, N.W. (1984) Social Interaction and Social Support. Journal of Social Issues, 40, 55-76. http://dx.doi.org/10.1111/j.1540-4560.1984.tb01107.x

[25] Ekman, P. and Friesen, W. (1971) Constants across Cultures in the Face and Emotion. Journal of Personality and Social Psychology, 17, 124-129. http://dx.doi.org/10.1037/h0030377

[26] Ledoux, J. (2003) The Emotional Brain, Fear and the Amygdala. Cellular and Molecular Neurobiology, 23, 727-738. http://dx.doi.org/10.1023/A:1025048802629

[27] Olsson, A. and Phelps, E. (2007) Social Learning of Fear. Nature Neuroscience, 10, 1095-1102.

[28] Goffman, E. (1963) Stigma: Notes on the Management of Spoiled Identity. Simon and Schuster Inc., New York.

[29] Corrigan, P. and Watson, A. (2002) The Paradox of Self-Stigma and Mental Illness. Clinical Psychology: Science and Practice, 9, 35-53. http://dx.doi.org/10.1093/clipsy.9.1.35

[30] Rao, D., Kekwaletswe, T.C., Hosek, S., Martinez, J. and Rodriguez, F. (2007) Stigma and Social Barriers to Medication Adherence with Urban Youth Living with HIV. AIDS Care, 19, 28-33. http://dx.doi.org/10.1080/09540120600652303

[31] Nyblade, L.C. (2006) Measuring HIV Stigma: Existing Knowledge and Gaps. Psychology Health and Medicine, 11, 335-345. http://dx.doi.org/10.1080/13548500600595178

[32] Sayles, J., Wong, M., Kinsler, J., Martins, D. and Cunningham, W. (2009) The Association of Stigma with Self-Reported Access to Medical Care and Antiretroviral Therapy Adherence in Persons Living with HIV/AIDS. Journal of General Internal Medicine, 24, 1101-1108. http://dx.doi.org/10.1007/s11606-009-1068-8

[33] Lee, R.S., Kochman, A. and Sikkema, K.J. (2002) Internalized Stigma among People Living with HIV-AIDS. AIDS and Behavior, 6, 309-319. http://dx.doi.org/10.1023/A:1021144511957

[34] Haug, N., Sorensen, J., Lllo, N., Gruber, V., Deluchhi, K. and Hall, S. (2005) Gender Differences among HIV-Methadone Maintenance Patients Enrolled in a Medication Adherence Trial. AIDS Care, 17, 1022-1029. http://dx.doi.org/10.1080/09540120500100882

[35] Tapp, C., Milloy, M., Kerr, T., Zhang, R., Guillemi, S., Hogg, R., Montaner, J. and Wood, E. (2011) Female Gender Predicts Lower Access and Adherence to Antiretroviral in a Setting of Free Healthcare. BMC Infectious Diseases, 11, 86. http://dx.doi.org/10.1186/1471-2334-11-86

[36] Jones, D.L., McPherson-Baker, S., Lydston, D., Camille, J., Brondolo, E., Tobin, J.N. and Weiss, S.M. (2007) Efficacy of a Group Medication Adherence Intervention among HIV Positive Women: The SMART/EST Women's Project. AIDS and Behavior, 11, 79-86. http://dx.doi.org/10.1007/s10461-006-9165-8

[37] Stone, V.E., Hogan, J.W., Schuman, P., Rompalo, A.M., Howard, A.A., Korkontzelou, C. and Smith, D.K. (2001) Antiretroviral Regimen Complexity, Self-Reported Adherence, and HIV Patient's Understanding of Their Regimens: Survey of Women in the HER Study. Journal of Acquired Immune Deficiency Syndrome, 28, 124-131. http://dx.doi.org/10.1097/00042560-200110010-00003

[38] Kalichman, S.C., Ramachandran, B. and Catz, S. (1999) Adherence to Combination Antiretroviral Therapies in HIV Patients of Low Literacy. Journal of General Internal Medicine, 14, 267-273. http://dx.doi.org/10.1046/j.1525-1497.1999.00334.x

[39] Paasche-Orlow, M.K., Cheng, D.M., Palepu, A., Meli, S., Faber, V. and Samet, J.H. (2006) Health Literacy, Antiretroviral Adherence, and HIV-RNA Suppression: A Longitudinal Perspective. Journal of General Internal Medicine, 21, 835-840. http://dx.doi.org/10.1111/j.1525-1497.2006.00527.x

[40] Gordillo, V., Smo, J., Soriano, V. and González-Lahoz, J. (1999) Sociodemographic and Psychological Variables Influencing Adherence to Antiretroviral Therapy. AIDS, 13, 1763-1769. http://dx.doi.org/10.1097/00002030-199909100-00021

[41] Levine, P. (2010) In an Unspoken Voice: How the Body Releases Trauma and Restores Goodness. North Atlantic Books, Berkeley.

[42] Rao, D., Feldman, B., Fredericksen, R., Crane, P., Simoni, J., Kitshata, M. and Crane, H. (2012) A Structural Equation Model of HIV-Related Stigma, Depressive Symptoms, and Medication Adherence. AIDS and Behavior, 16, 711-716. http://dx.doi.org/10.1007/s10461-011-9915-0 